\title{
Strengths-based actions to enhance wellbeing in the time of COVID-19
}

\author{
Tayyab Rashid · Robert E. McGrath
}

\begin{abstract}
COVID-19 is truly an unprecedented event, forcing nearly four billion people into isolation, social distancing, and requiring people to rigorously follow public health measures such as frequent hand washing and indoor face-covering. People around the world have spent months staying home-bound, enduring significant financial, social, and emotional costs. They have been feeling anxious, irritable, afraid, and ambivalent in the wake of an invisible, pervasive, and potent pandemic. A strength focus can help us mitigate unwarranted or excessive negative emotions engendered by maintaining social distancing. This paper posits that by using our strengths, we can enhance our psychological immunity through pragmatic actions to enhance our daily wellbeing. More importantly, we can reframe and reappraise challenges to build perspective in dealing with global crises such as pandemics and disasters. Strengths expressed through pragmatic actions can boost our coping skills as well as enhance our wellbeing. Consistent with the zeitgeist of our times-equity, social justice, digital connections, the paper offers easily implemented, concrete actions using character strengths in adaptive ways to reduce the likelihood that social distancing will result in overwhelming anxiety, lack of structure or stimulation, and demoralization.
\end{abstract}

Keywords: character strengths, crises, pandemics, positive psychology interventions, social distancing, COVID-19

\section{Applications:}

1. Managing Public Health Crisis. Nearly every person on this planet has been affected - in one way or another - by COVID-19. To mitigate the transmission of the virus, social isolation, social distancing and following public health measures rigorously for prolonged period of time is required, with no end in sight. This can increase psychological distress and decrease wellbeing. The ability to effectively manage public health crisis, emotional stability and psychological wellbeing is critical.

2. Culturally Responsive Treatments. COVID-19 has exposed significant health and mental health inequalities that have existed for decades. Working in low wage but essential care and services positions, ethnic minorities, have suffered disproportionately from the adverse impact of COVID-19. There is an urgent need to systematically identify the most vulnerable individuals and offer them culturally responsive treatments.

3. Amplification of Strengths. Assessment and amelioration of symptoms should be taken seriously. Equally important is the assessment and amplification of strengths. A strengths-focused mental health approach will likely reduce stigma that hinders seeking treatment in a timely fashion. 


\section{Introduction}

Epidemics, plagues, and pandemics have been part of human history, but COVID-19 is truly unprecedented. It has forced an estimated four billion people into social isolation (Sanford, 2020). Unless a safe vaccine becomes available and the majority of people take it, social isolation, social distancing, face-covering, frequent hand washing, and remote connection might be the norm. Pandemics, like large scale natural disasters, create significantly disruptions (Lau et al., 2003) and COVID-19 is no exception. The data from an international study performed as a collaboration between 41 research organizations from 47 countries representing Europe, North-Africa, Western Asia and Americas, completed in seven languages, with 1047 participants was collected in early April 2020 (Ammar et al., 2020). The study assessed wellbeing, life satisfaction, social participation, diet behaviour, sleep quality, technology use, and psychosocial support. Questions were presented in a deferential format with items related to responses "before" and "during" confinement conditions. The study found significant psychosocial strain in terms of large decreases in the amount of social activity through family $(58 \%)$, friends/neighbours $(45 \%)$, and entertainment (48\%). Social participation was associated with lower life satisfaction (31\%) during the confinement period. Social contact through digital means increased significantly $(25 \%)$. The study concluded that there is an acute need for innovative strategies which promote social inclusion through digital solutions. An Italian study found significant increases in depression and anxiety, when compared with pre-outbreak levels (Baiano et al., 2020). However, not everyone develops clinical level of depression or anxiety. A French study explored the role of emotional experience as a critical factor in the experience of time. The study found evidence for the famous expression "time flies when you feel good; time drags when you feel bad." Participants reported a slowing down of time as both sadness and boredom increased (Witowska et al, 2020). When considering these factors, it is unsurprising that the cumulative impact of this global phenomenon will be profound (Stanford, 2020). People have spent months in close quarters to 'flatten the curve' and have endured significant financial, social and psychological costs (Torales et al., 2020).

The curve, however, has an uneven impact, adversely impacting marginalized, ethnic, indigenous, and immigrant communities when compared to Caucasians. A retrospective cohort analysis of 1052 confirmed cases of COVID-19 from the period January 1 through April 8, 2020, found that compared to non-Hispanic white patients, non-Hispanic African American patients were 2.7 times more likely to be hospitalized, after adjustment for age, sex, comorbidities, and income. Researchers attributed this to barriers to timely access to care or creation of circumstances in which patients were delayed care (Yearby \& Mohapatra, 2020). COVID-19 has brought to light similar significant health and mental health inequalities that have existed for decades. Due to these chronic inequalities, racial and ethnic minorities have always been the most impacted by pandemics because of disparities in; exposure to the virus, susceptibility to contracting the virus, and quality of treatment. Additionally, most marginalized communities are especially employed in low wage critical infrastructure health and other services (Dee et al., 2011; McLeod et al., 2020; Navaranjan et al., 2014). Recall your last health care visit or use of public transit, how many health care and transit staff from a Non-White cultural background have you encountered? Compared to many professionals - the majority of whom tend to be White, heterosexual, privileged, and males - who can work from home, the majority of people of colour, especially recent immigrants with heath care training and expertise, have no choice but to leave the safer confines of their homes every day to go to work, increasing their exposure to the virus. Many do not have the choice to do telemedicine and must travel to their workplace on crowded public transit, putting them and their families at risk of contracting virus. To make 
matters worse, many marginalized workers work on a contractual basis without the benefits of paid sick days and are in constant fear of losing their jobs. This additional factor puts them and their families at further risk. Furthermore, low wage workers often live in small apartments, with multi-generational families which further increases the risk of virus transmission (Azar et al., 2020; Dorn et al., 2020; Krouse, 2020).

COVID-19 with its potential multiple peaks and waves, already has and will likely continue to have profound impacts on the day to day wellbeing of individuals. Early indicators have shown that the most stressful experiences regarding COVID-19 are; a) reading/hearing about severity and contagiousness of COVID-19; b) uncertainty about length of quarantine; and c) social distancing requirements. Younger, women and caregivers tend to experience more stress. There have been dramatic shifts in sleep, diet, physical activity, substance abuse as well as in dramatic increase in intimate partner violence (Arora \& Grey, 2020; Buttell, \& Ferreira, 2020). The most common coping strategies used are distracting, information seeking and consuming social media (Klaiber et al., 2020)

The goal of the current paper is to highlight how these challenges adversely impact day-today wellbeing and how we can use our strengths to take adaptive, pragmatic, and purposeful actions which are relevant to our wellbeing and use our strengths.

It is understandable that with the easing of restrictions, restless for months and bored, people are adjusting to the new normal amidst a global pandemic with uncertainty-unsure how to operate in the different public spheres - when and where to mask our faces, how to physically distance in settings that are designed to connect us, and how to redesign work for an online format. These everyday challenges have significantly increased worry and anxiety, when compared to before the COVID-19 outbreak (Baiano et al., 2020). Some have even entertained supernatural beliefs about COVID-19 (Somma et al., 2020). Eventually, it is hoped that a vaccine will dispel worries and decrease anxiety. However, the cumulative impact of social distancing, persistent fear and anxiety will likely be significant. In order to effectively deal with this prolonged pandemic, with no clear end in sight, a comprehensive and inclusive psychological support system which meets the needs of most, if not all, is perhaps as crucial as public health measures (Wang et al., 2020). The primary goal of this paper is to offer individuals, dyads, and families various inexpensive, practical, simple ideas which they can implement easily.

\section{Coping with natural disasters, technological catastrophes and pandemics}

Prior experiences can help us in understanding how to cope with these challenges. Natural disasters (e.g., earthquakes, floods, tornados), technological catastrophes (e.g., nuclear and hazardous material spills, plane crashes), and pandemics (e.g., severe acute respiratory syndrome, avian or bird flu, Ebola virus, coronavirus) are all collective experiences impacting individuals, families, and communities that we have dealt with before. Exposure to these events is associated with both negative and positive outcomes (Fergusson \& Boden, 2014; Naushad et al., 2019). In particular, a systematic analysis of 41 studies that compared individuals exposed to a range of natural disasters to their pre-exposure state or a non-exposed comparison group were found to have higher levels of psychiatric disorders, especially post-traumatic stress disorder and depression (Beaglehole et al., 2018). Feeling anxious, irritable, afraid, and demoralized in the wake of a disaster as invisible, pervasive, and potent as a pandemic, makes sense. As noted above, marginalized populations are disproportionately affected by such disasters, not only in the United States, but across the globe (Shuchman, 2020; Yearby \& Mohapatra, 2020), resulting in more severe mental health effects (Burgess, 2020; Ornell et al., 2020; Potent et al., 2020). Traditional interventions may not be culturally relevant or may have limited effectiveness in the 
face of cultural obstacles faced by disadvantaged populations. Consider a Hispanic woman who will lose her income if she quits working in close quarters with others, or a Black man, wearing a mask, trying to purchase groceries, operating under the fear that normal daily activities will devolve into a confrontation with law enforcement officers. Traditional intervention may not be effective, given that COVID-19 is evolving rapidly. There are no psychological interventions to deal with COVID-19 specific concerns. Existing treatments, nonetheless, can offer supportive care. There is room for effective psychological treatments which address pandemic specific concerns such as social isolation, health anxiety and differential impact on marginalized populations (Hansel et al., 2020; Holmes et al., 2020). The literature on the mental health consequences of epidemics is sparse (Galea et al., 2020), but the mental health consequences of large-scale disasters (e.g., terrorists attacks, extreme weather events, and industrial disasters) have been documented (Galea et al., 2002; Gratten et al., 2011; Tracy et al., 2011). During the 2014 West Africa Ebola outbreak, informal networks and support groups of Ebola virus disease survivors were formed somewhat spontaneously to support recovered individuals (Epstein et al., 2014). Such psycho-social interventions can be encouraged and can play an important role in helping people to cope with residual impacts of COVID-19. Despite the lack of knowledge as to which psychological treatments are more relevant to treat COVID-19 related issues, their importance as supportive care should not be minimized and these can still be very helpful in dealing with symptoms of depression, anxiety and overall psychological distress (Holder et al., 2017).

A strengths focus offers another path to help us mitigate unwarranted or excessive worry, anxiety, and demoralization. Exploring and using our strengths can enhance our immunity to stressors by building protective and pragmatic habits and actions. Applying our strengths helps us to reframe and reappraise challenges, and potentially provides us with a steady dose of wellbeing to build positive coping mechanisms (Baker et al., 2017). A strengths-based approach may even be more effective for marginalized populations, in which traditional approaches to mental health that focus on deficiencies in the individual can result in further demoralization, and avoids the stigmatization resulting from diagnoses that may not adequately encapsulate the socio-economic and cultural experiences of these populations (Samson, 2018; Zalaquett et al., 2008). Compared to an approach that focuses on symptom alleviation, a strengths focus can be more normalizing and engaging (Niemiec \& McGrath, 2018; Rashid \& Seligman, 2018). We offer 101 easily implemented, concrete actions that build on yours and others' strengths in this period of isolation and uncertainty (see Appendix A).

Tuning in to constant media coverage while being stuck at home can dramatically contribute to negative consequences (Balaratnasingam \& Janca, 2006). Work, school, and services shutdowns, combined with directives for social distancing, anxiety and fear can quickly turn into panic and terror. When we experience anxiety or demoralization in response to stressors, that can serve as a signal that it is time to engage in protective behaviour. Tapping into our character strengths - the main ingredients of our character - can help us mitigate unwarranted or excessive fear, anxiety and demoralization. Focusing on our character strengths, not our sense of fear or rage, offers a path to enhancing our psychological immunity.

\section{Character strengths}

Character strengths can be conceptualized in a number of ways. Christopher Peterson and Martin Seligman (2004) offered a coherent model of such strengths, called the VIA (Values in Action) Classification of Character Strengths and Virtues (CSV; Peterson \& Seligman, 2004). According to the CSV model, character strengths are traits or attributes of the individual that are 
ubiquitously valued in their own right. Unlike feelings of panic or demoralization that can leave us feeling isolated, character strengths used in a balanced and contextualized way generally boost one's self-confidence and sense of efficacy (Niemiec \& McGrath, 2019). The CVS outlines 24 character strengths, divided into six broader categories referred to as virtues (see Table 1): Knowledge \& Wisdom, Courage, Humanity, Justice, Temperance and Transcendence.

\section{Table 1. VIA Classification of Character Strengths and Virtues.}

\section{Wisdom and Knowledge - Cognitive strengths that entail the acquisition and use of knowledge}

Creativity [originality, ingenuity]: Thinking of novel and productive ways to conceptualize and do things; includes artistic achievement but is not limited to it

Curiosity [interest, novelty-seeking, openness to experience]: Taking an interest in ongoing experience for its own sake; finding subjects and topics fascinating; exploring and discovering

Judgment [critical thinking]: Thinking things through and examining them from all sides; not jumping to conclusions; being able to change one's mind in light of evidence; weighing all evidence fairly

Love of Learning: Mastering new skills, topics, and bodies of knowledge, whether on one's own or formally; obviously related to the strength of curiosity but goes beyond it to describe the tendency to add systematically to what one knows

Perspective [wisdom]: Being able to provide wise counsel to others; having ways of looking at the world that make sense to oneself and to other people

II. Courage - Emotional strengths that involve the exercise of will to accomplish goals in the face of opposition, external or internal

Bravery [valor]: Not shrinking from threat, challenge, difficulty, or pain; speaking up for what is right even if there is opposition; acting on convictions even if unpopular; includes physical bravery but is not limited to it

Perseverance [persistence, industriousness]: Finishing what one starts; persisting in a course of action in spite of obstacles; "getting it out the door"; taking pleasure in completing tasks

Honesty [authenticity, integrity]: Speaking the truth but more broadly presenting oneself in a genuine way and acting in a sincere way; being without pretense; taking responsibility for one's feelings and actions

Zest [vitality, enthusiasm, vigor, energy]: Approaching life with excitement and energy; not doing things halfway or half-heartedly; living life as an adventure; feeling alive and activated

\section{Humanity - Interpersonal strengths that involve tending and befriending others}

Love: Valuing close relations with others, in particular those in which sharing and caring are reciprocated; being close to people

Kindness [generosity, nurturance, care, compassion, altruistic love, "niceness"]: Doing favors and good deeds for others; helping them; taking care of them

Social Intelligence [emotional intelligence, personal intelligence]: Being aware of the motives and feelings of other people and oneself; knowing what to do to fit into different social situations; knowing what makes other people tick

\section{Justice - Civic strengths that underlie healthy community life}

Teamwork [citizenship, social responsibility, loyalty]: Working well as a member of a group or team; being loyal to the group; doing one's share

Fairness: Treating all people the same according to notions of fairness and justice; not letting personal feelings bias decisions about others; giving everyone a fair chance

Leadership: Encouraging a group of which one is a member to get things done and at the time maintain time good relations within the group; organizing group activities and seeing that they happen

\section{Temperance - Strengths that protect against excess}

Forgiveness: Forgiving those who have done wrong; accepting the shortcomings of others; giving people a second chance; not being vengeful

Humility: Letting one's accomplishments speak for themselves; not regarding oneself as more special than one is

Prudence: Being careful about one's choices; not taking undue risks; not saying or doing things that might later be regretted 
Self-Regulation [self-control]: Regulating what one feels and does; being disciplined; controlling one's appetites and emotions

VI. Transcendence - Strengths that forge connections to the larger universe and provide meaning Appreciation of Beauty and Excellence [awe, wonder, elevation]: Noticing and appreciating beauty, excellence, and/or skilled performance in various domains of life, from nature to art to mathematics to science to everyday experience

Gratitude: Being aware of and thankful for the good things that happen; taking time to express thanks

Hope [optimism, future-mindedness, future orientation]: Expecting the best in the future and working to achieve it; believing that a good future is something that can be brought about

Humor [playfulness]: Liking to laugh and tease; bringing smiles to other people; seeing the light side; making (not necessarily telling) jokes

Spirituality [faith, purpose]: Having coherent beliefs about the higher purpose and meaning of the universe; knowing where one fits within the larger scheme; having beliefs about the meaning of life that shape conduct and provide comfort

Note. Adapted from Character Strengths and Virtues: A Handbook and Classification (pp. 29-30), by C. Peterson \& M. E. P. Seligman, 2004, American Psychological Association/Oxford University Press. Copyright 2004 by the Values in Action Institute. Adapted with permission. Terms in brackets are variants of the character strength according to Peterson and Seligman (2004). Embedded hyperlinks refer to specific character strength pages at the VIA website (www.viacharacter.org) offering an overview of the signature strengths, critical questions, illustrations and summary of research findings. We have used the most updated titles of character strengths, consistent with Values in Actions website. These may differ slightly from original titles published by C. Peterson. \& M. E. P. Seligman (2004).

Since the introduction of the CSV model in 2004, hundreds of studies have been conducted exploring the role of character strengths in education, work, health and numerous other domains (see Niemiec, 2018, for a review).

\section{Using Character Strengths amidst COVID-19}

Why would using character strengths be a useful way to respond to the fear and stress caused by a pandemic? First, our strengths are as a natural part of our personalities as our weakness are. Our sense of kindness, zest, or curiosity is a core part of who we are. One part of the CSV model is the idea that for any person, some strengths are so central to an individual that they can be called signature strengths. Researchers have suggested that on average people identify five of the 24 strengths as signature (McGrath, 2019; Peterson \& Seligman, 2004). Individuals typically describe these strengths as essential to who they are, naturally energizing, and easy to use. For example, a person for whom creativity is a signature strength might realize she automatically searches for creative solutions whenever faced with a problem. A person for whom kindness is a signature strength may feel renewed whenever he engages in kindness or sees someone else acting kindly. Actively using one's signature strengths can be a way for us to make contact with positive feelings (Shoshani \& Slone, 2016).

Signature strengths have been operationalized into pragmatic strategies. Often delivered online, these are relatively simple strategies to increase wellbeing. Seligman et al. (2005) empirically validated three strength-based interventions: Three Good Things, also known as Blessings Journal; Using Signature Strengths in a New Way; and Gratitude Visit. Numerous independent researchers have replicated these findings (Gander et al., 2013; Martinez-Marti \& Ruch, 2014; Mongrain \& Anselmo-Mathews, 2012; Odou \& Vella-Brodrick, 2013; Quinlan et al., 2015; Schotanus-Dijkstra et al., 2015; Winslow et al., 2016). A number of systematic reviews and meta-analyses have documented the effectiveness of strength-based interventions (Bolier et al., 2013; Chakssi et al., 2018; Ghielen et al., 2017; Quinlan et al., 2015). A recent meta-analysis 
(Schutte \& Malouff, 2019) of 14 studies has demonstrated that signature strengths interventions increased positive affect and happiness (weighted mean Hedges' $g$ of 0.32) and life satisfaction $(g=0.42)$, and decreased depression $(g=0.21)$. However, research on strength-based interventions has a long way to go, with a need for more diverse samples and more behavioural outcomes (e.g., improved sleep, more time spent in interacting with loved ones, number of volunteer hour). That said, we have several reasons to believe a strengths-based approach can offer a valid alternative to traditional psychological treatments: First, focusing on strengths rather than our negative feelings or inadequacies when dealing with extreme stress can make those negative thoughts and feelings less powerful. It can remind us that we have our personal strengths that can carry us through the crisis (Shoshani \& Slone, 2016).

Second, one important feature of character strengths - one of the reasons they are so widely valued - is that they contribute to us as individuals, but also to those around us, and even at times to the entire community. Being able to use humor in dark times, love to reach out to others, or gratitude to make someone else who has done something good focus on it and feel better: these simple acts help others feel stronger and more positive even while they do the same thing for us (Davis et al., 2016). An important element of character strengths is that using them to benefit ourselves does not diminish others.

Third, emerging lines of researchers have shown that, in addition to increasing wellbeing, interventions based in character strengths also have the potential for alleviating or ameliorating negatives states and symptoms associated with stressful events, including providing psychological support in recovering from breast cancer (Casella-Grau et al., 2014), learning to cope with difficult emotions (Quoidbach \& Gross, 2015; Uliaszek et al., 2016), recovery from drug addiction (Krentzman, 2013), dealing with chronic physical illness (Ghosh \& Deb, 2017), promoting healthy behaviour in the wake of cardiovascular disease (Celano et al., 2018), coping with chronic illness (Yan et al., 2020), and potentially decreasing the perceived stress related to care-giving (García-Castro et al., 2020).

Finally, focusing on strengths can motivate us to respond more effectively to the challenges we face. Strengths can be used to deal with those challenges adaptively, to come up with new solutions for the obstacles created by natural disaster (Southwick et al., 2016). Consider the frontline professionals dealing with COVID-19, including but not limited to doctors, nurses, paramedics, first responders, and nursing home staff. They are exposed to repetitive trauma as part of their work. Researchers have indicated that a substantial proportion of these providers may develop symptoms of anxiety, including posttraumatic stress disorder, depression, alcohol abuse, and medical concerns (Naushad et al., 2019). Yet, they are driven by their sense of humanity, teamwork, kindness and fairness to continue. Quevillon and colleagues (2016) found that opportunities for professional and personal growth can help buffer frontline workers against mental health problems. Character strengths can serve as central ingredients for fostering such growth. Therefore, the potential value of a focus on one's character strengths during times of disaster is not purely speculative.

Researchers have found in previous studies that strengths can be a protective factor in the face of negative life events such as COVID-19. For example, a randomized study that used strength-based case management with individuals who were HIV positive was found to be more effective than usual care (Samet et al., 2019). Another example of the protective factor of strengths includes homeless youth who when asked to describe their key personal strengths, reliably identified attributes consistent with the 24 VIA character strengths. They anecdotally considered those strengths to be vital protective factors in their lives. The degree to which their actual use of strengths that were important to them matched their ideal use, and was also correlated with 
resilience, self-worth, and wellbeing (Cooley et al., 2019). Similarly, Sleijpen and colleagues (2018) examined 26 empirical studies exploring sources of resilience in young refugees. Among other factors, the character strength of spirituality was reliably associated with resilience. In the context of natural disasters such as facing devastation from floods, those who were able to embrace, rebuild, and develop inner strength demonstrated transformational perspectives on self and the world (Rateau, 2017). Kampman and colleagues (2015) synthesized qualitative findings on posttraumatic growth following severe physical injuries. Several of the themes they identified were consistent with the VIA virtues of Humanity and Transcendence. Finally, Blanchard et al. (2020) found that depression and functional impairment in individuals who had suffered a significant interpersonal loss in the previous six months (death of a first-degree relative or divorce) had a negative relationship with 11 of the 24 VIA character strengths.

\subsection{Character strengths in disasters}

Based on these research findings, we can suggest at least five ways in which character strengths can play a vital role in enhancing the effectiveness of psychological care in the context of wide scale disasters by facilitating individual and community preparedness, resilience, meaningmaking and potential posttraumatic growth (Southwick et al., 2016). First, the ability to make meaning of disaster events has been found to be a strong predictor of overall resilience (Aiena et al., 2016). Character strengths such as perspective, judgment, and spirituality can provide a pragmatic foundation for developing a sense of the implications of this pandemic for the larger scheme of our existence.

Second, being aware of and affirming our most important strengths can help us to reinterpret and reframe our fear about the pandemic. When we are stressed, our focus becomes narrow, and we tend to attend to selective aspects of a situation (Fredrickson et al., 2003). Approaching disasters from the perspective of our strengths can enable us to personalize the experience in a way that enhances the effectiveness of our responses. For example, the ability to navigate a disaster can be enhanced by actively experiencing gratitude for loved ones' good efforts, even minor efforts such as helping around the house; by learning about others' acts of responsible citizenship and personally engaging in good citizenship; by reflecting and sharing with loved ones a personal perspective on the pandemic; and by looking with hope towards a brighter future.

Third, using our strengths during a pandemic can provide us with a steady dose of wellbeing in ways which focusing on our vulnerabilities cannot. For example, research shows that helping others also contributes to the actor's wellbeing (Meyer et al., 2018). More than ever, it can be important for us to look for opportunities to be kind to someone who is struggling. Whereas negative emotions such as fear, anxiety and panic can paralyze us or threaten our wellbeing, using strengths such as creativity, hope and optimism, self-regulation, gratitude, social intelligence, kindness, and-perhaps most importantly-perspective, help us take action and overcome adversity.

Fourth, challenges such as a global pandemic allow us to re-examine our priorities in life, reappraise what we value, and evaluate whether our actions match with upholding these values (Yang, 2020). For example, the COVID-19 pandemic has reminded us about the importance of our physical health. We can use strengths to pursue physical health more effectively, e.g., by thinking about the beauty in the world when we try to go to sleep rather than our fears, or by using prudence to avoid eating while bored.

Finally, it is important to remember that, while the term social distance has been widely adopted, what we mean by that is physical distance; social distance need not imply social isolation. 
In a time of social distancing, strengths use can offer us multiple ways to remain connected in prosocial and positive ways. Our repertoire of strengths can still connect us to our social networks. Strengths can facilitate three distinct aspects of social support (Jacobs et al., 2016; Kaniasty \& Norris, 2009). First, a strengths approach reduces the stigma and alienation that can come from conceptualizing struggles as a mental health issue (Vertilo \& Gibson, 2012). Second, spotting others' strengths can help us more effectively ask others for help (e.g., Skeffington et al., 2016). Third, knowing and using one's strengths can increase social competence in the context of the improved quality of social relationships, enhanced feelings of competence, increased altruistic behaviour, and more meaningful leisure activity (Fruel et al., 2001; Kashdan et al., 2006). Though social support is an important contributor to being able to cope with challenges (Prati \& Pietrantoni, 2010), we need to keep in mind that the value of social supports should be viewed within a larger socio-economic and cultural milieu. For example, an individual from a marginalized community may be well-connected with other community members, but the community itself may not have sufficient resources such as disposable income, infrastructure, or time to help due to long work hours.

\subsection{Adaptive use of character strengths while being home-bond}

How do we effectively use our strengths to cope more effectively while staying home and maintaining physical distance? The list of 101 examples in Appendix A attempts to translate the abstract notions of character strengths into concrete and pragmatic actions that do not take a lot of effort and can produce desirable results quickly. Each action is associated with one or more strengths, with hyperlinks to specific page of the VIA Website (www.viacharacter.org) which offers a comprehensive review of each of the 24 strengths, critical questions, illustrations, and a summary of empirical findings. One can complete a free strengths measure and receive instantaneous feedback. Please note that these strategies are intended for individuals and families who may be spending more time at home due to the COVID-19 pandemic but are not infected. Most, if not all, of these actions engage multiple strengths, as noted in parentheses. Certain strengths such as kindness are more represented than humility. This imbalance is in part due to the specific challenges related to COVID-19. These actions have been largely distilled from the first author's nearly two decades of experience trying to integrate character strengths with mental health symptoms in clinical settings (Rashid \& Seligman, 2018), with substantial input from the second author. ${ }^{1}$

In summary, the negative emotions that are engendered by natural disasters call for making available traditional methods of intervention for clinical syndromes. However, these approaches can be complemented by a more positively focused, strengths-based perspective, one that relies on the individual's existing capacities for effective functioning. Instead of stigmatizing to individuals who are already disadvantaged, we believe a strengths approach can be empowering, and provide a valuable new avenue for taking on the task of managing the demands of a world in upheaval.

\section{Conflict of interest statement}

The authors report no conflicts of interest.

\footnotetext{
${ }^{1}$ We are also deeply grateful to Deborah Bernstein for her extensive input on the list. We are also thankful for Zachary Zarowsky for his assistance with the organization of the article.
} 


\section{Authors}

Tayyab Rashid

Health \& Wellness Centre

University of Toronto Scarborough

tayyab.rashid@utoronto.ca

Robert E. McGrath

Fairleigh Dickinson University

\section{Publishing Timeline}

Received 24 April 2020

Revised version received 25 September 2020

Accepted 29 September 2020

Published 30 September 2020

\section{References}

Adirim, T. A. (2020, July 8). Coronavirus Pandemic: Racial and Ethnic Disparities in COVID-19 Outbreak Amplifies Health Inequalities in Palm Beach Country. Palm Beach Post, 13.

Aiena, B. J., Buchanan, E. M., Smith, C. V., \& Schulenberg, S. E. (2016). Meaning, resilience, and traumatic stress after the Deepwater Horizon oil spill: A study of Mississippi coastal residents seeking mental health services. Journal of Clinical Psychology, 72(12), 1264-1278. https://doi.org/10.1002/jclp.22232

Ammar, A., Chtourou, H., Boukhris, O., Trabelsi, K., Masmoudi, L., Brach, M., Bouaziz, B., Bentlage, E., How, D., Ahmed, M., Mueller, P., Mueller, N., Hsouna, H., Aloui, A., Hammouda, O., PaineirasDomingos, L., Braakman-Jansen, A., Wrede, C., Bastoni, S., ... Hoekelmann, A. (2020). COVID-19 Home Confinement Negatively Impacts Social Participation and Life Satisfaction: A Worldwide Multicenter Study. International Journal of Environmental Research and Public Health, 17, 6237. https://doi.org/10.3390/ijerph17176237

Arora, T., \& Grey, I. (2020). Health behaviour changes during COVID-19 and the potential consequences: A mini-review. Journal of Health Psychology, 25(9), 1155-1163. https://doi.org/10.1177/1359105320937053

Azar, K. M. J., Shen, Z., Romanelli, R. J., Lockhart, S. H., Smits, K., Robinson, S., Brown, S., \& Pressman, A. R. (2020). Disparities in outcomes among COVID-19 patients in a large health care system in California: Study examines disparities in access and outcomes for COVID-19 patients who are members of racial and ethnic minorities and socioeconomically disadvantaged groups. Health Affairs. https://doi.org/10.1377/hlthaff.2020.00598

Baker, J. C., Williams, J. K., Witvliet, C. V. O., \& Hill, P. C. (2017). Positive reappraisals after an offense: Event-related potentials and emotional effects of benefit-finding and compassion. The Journal of Positive Psychology, 12(4), 373-384. https://doi.org/10.1080/17439760.2016.1209540

Balaratnasingam, S., Janca, A. (2006). Mass hysteria revisited. Current Opinion in Psychiatry, 19, 171-174

Beaglehole, B., Mulder, R. T., Frampton, C. M., Boden, J. M., Newton-Howes, G., \& Bell, C. J. (2018). Psychological distress and psychiatric disorder after natural disasters: Systematic review and metaanalysis. The British Journal of Psychiatry, 213(6), 716-722. https://doi.org/10.1192/bjp.2018.210

Baiano, C., Zappullo, I., Group, T. L., \& Conson, M. (2020). Tendency to Worry and Fear of Mental Health during Italy's COVID-19 Lockdown. International Journal of Environmental Research and Public Health, 17(16), 5928. https://doi.org/10.3390/ijerph17165928

Blanchard, T., McGrath, R. E., Jayawickreme, E., \& Armeli, S. (2020). Resilience in the face of interpersonal loss: The role of character strengths. Manuscript submitted for publication.

Bolier, L., Haverman, M., Westerhof, G. J., Riper, H., Smit, F., \& Bohlmeijer, E. (2013). Positive psychology interventions: A meta-analysis of randomized controlled studies. BMC Public Health, 13, 119. https://doi.org/10.1186/1471-2458-13-119 
Bonanno, G. A., \& Mancini, A. D. (2012). Beyond resilience and PTSD: Mapping the heterogeneity of responses to potential trauma. Psychological Trauma: Theory, Research, Practice, and Policy, 4(1), 74-83. https://doi.org/10.1037/a0017829

Brooks, S. K., Webster, R. K., Smith, L. E., et al. (2020) The psychological impact of quarantine and how to reduce it: Rapid review of the evidence. The Lancet, 395: 912-920. https://doi.org/10.1016/S01406736(20)30460-8

Burgess, R. (2020, May 4). COVID-19 mental-health responses neglect social realities. Nature. https://doi.org/10.1038/d41586-020-01313-9

Buttell, F., \& Ferreira, R. J. (2020). The hidden disaster of COVID-19: Intimate partner violence. Psychological Trauma: Theory, Research, Practice, and Policy, 12, S197-S198. https://doi.org/10.1037/tra0000646

Casellas-Grau, A., Font, A., \& Vives, J. (2014). Positive psychology interventions in breast cancer. A systematic review. Psycho-Oncology,23, 9-19. https://doi.org/10.1002/pon.3353

Castro Solano, A., \& Consentino, A. C. (2016). The relationships between character strengths and life fulfillment in the view of lay-people in Argentina. Interdisciplinaria Revista de Psicología y Ciencias Afines, 33, 65-80. https://doi.org/10.16888/interd.2016.33.1.4

Celano, C. M., Freedman, M. E., Beale, E. E., Gomez-Bernal, F., \& Huffman, J. C. (2018). A Positive Psychology Intervention to Promote Health Behaviors in Heart Failure: A Proof-of-Concept Trial. The Journal of Nervous and Mental Disease, 206(10), 800-808. https://doi.org/10.1097/NMD.0000000000000883

Chakhssi, F., Kraiss, J. T., Sommers-Spijkerman, M., \& Bohlmeijer, E. T. (2018). The effect of positive psychology interventions on well-being and distress in clinical samples with psychiatric or somatic disorders: A systematic review and meta-analysis. BMC Psychiatry, 18, 211. https://doi.org/10.1186/s12888-018-1739-2

Cooley, S. J., Quinton, M. L., Holland, M. J. G., Parry, B. J., \& Cumming, J. (2019). The experiences of homeless youth when using strengths profiling to identify their character strengths. Frontiers in Psychology, 10, 2036. https://doi.org/10.3389/fpsyg.2019.02036

Davis, D. E., Choe, E., Meyers, J., Wade, N., Varjas, K., Gifford, A., . . Worthington, E. L., Jr. (2016). Thankful for the little things: A meta-analysis of gratitude interventions. Journal of Counseling Psychology, 63(1), 20-31. https://doi.org/10.1037/cou0000107

Dee, D. L., Bensyl, D. M., Gindler, J., Truman, B. I., Allen, B. G., D'Mello, T., Pérez, A., Kamimoto, L., Biggerstaff, M., Blanton, L., Fowlkes, A., Glover, M. J., Swerdlow, D. L., \& Finelli, L. (2011). Racial and ethnic disparities in hospitalizations and deaths associated with 2009 pandemic Influenza A (H1N1) virus infections in the United States. Annals of epidemiology, 21(8), 623-630. https://doi.org/10.1016/j.annepidem.2011.03.002

Dorn, A. v., Cooney, R. E., \& Sabin, M. L. (2020). COVID-19 exacerbating inequalities in the US. The Lancet (British Edition), 395(10232), 1243-1244. Fergusson, D. M., \& Boden, J. M. (2014). The psychological impacts of major disasters. Australian \& New Zealand Journal of Psychiatry, 48(7), 597599. https://doi.org/10.1177/0004867414538677

Epstein, J. M., Sauer, L. M., Chelen, J., Hatna, E., Parker, J., Rothman, R. E., \& Rubinson, L. (2014). Infectious disease: Mobilizing Ebola survivors to curb the epidemic. Nature, 516(7531), 323-325. https://doi.org/10.1038/516323a

Frueh, B. C., Turner, S. M., Beidel, D. C., \& Cahill, S. P. (2001). Assessment of social functioning in combat veterans with PTSD. Aggression and Violent Behavior, 6(1), 79-90. https://doi.org/10.1016/S13591789(99)00012-9

Fredrickson, B. L., Tugade, M. M., Waugh, C. E., \& Larkin, G. R. (2003). What good are positive emotions in crisis? A prospective study of resilience and emotions following the terrorist attacks on the United States on September 11th, 2001. Journal of Personality and Social Psychology, 84, 365-376.

Gander, F., Proyer, R., Ruch, W., \& Wyss, T. (2013). Strength- based positive interventions: Further evidence for their potential in enhancing well-being and alleviating depression. Journal of Happiness Studies, 14(4), 1241-1259. https://doi.org/10.1007/s10902-012-9380-0 
Galea, S., Merchant, R. M., \& Lurie, N. (2020). The mental health consequences of COVID-19 and physical distancing: The need for prevention and early intervention. JAMA Internal Medicine, 180(6), 817-818. https://doi.org/10.1001/jamainternmed.2020.1562

García-Castro, F. J., Alba, A., \& Blanca, M. J. (2020). Association Between Character Strengths and Caregiver Burden: Hope as a Mediator. Journal of Happiness Studies, 21(4), 1445-1462. https://doi.org/10.1007/s10902-019-00138-2

Ghielen, S. T. S., van Woerkom, M., \& Christina Meyers, M. (2017). Promoting positive outcomes through strengths interventions: A literature review. The Journal of Positive Psychology, 13(6), 573-585. https://doi.org/10.1080/17439760.2017.1365164

Ghosh, A., \& Deb, A. (2017). Positive Psychology Interventions for Chronic Physical Illnesses: A Systematic Review. Psychological Studies, 62(3), 213-232. https://doi.org/10.1007/s12646-017-0421-y

Havnen, A., Anyan, F., Hjemdal, O., Solem, S., Gurigard Riksfjord, M., \& Hagen, K. (2020). Resilience Moderates Negative Outcome from Stress during the COVID-19 Pandemic: A Moderated-Mediation Approach. International Journal of Environmental Research and Public Health, 17(18), 6461. https://doi.org/10.3390/ijerph17186461

Hansel, T., Saltzman, L., \& Bordnick, P. (2020). Behavioral Health and Response for COVID-19. Disaster Medicine and Public Health Preparedness, 1-7. https://doi.org/10.1017/dmp.2020.180

Holder, N., Surís, A., Holliday, R., \& North, C. S. (2017). Principles of mental health intervention for survivors of major disasters. Psychiatric Annals, 47(3), 124-127. https://doi.org/10.3928/0048571320170202-01

Holmes, E. A., O'Connor, R. C., Perry, V. H., et al. (2020). Multidisciplinary research priorities for the COVID-19 pandemic: A call for action for mental health science. The Lancet Psychiatry 7(6):547-560.

Jacobs, G. A., Gray, B. L., Erickson, S. E., Gonzalez, E. D., \& Quevillon, R. P. (2016). Disaster mental health and community-based psychological first aid: Concepts and education/training. Journal of Clinical Psychology, 72(12), 1307-1317. https://doi.org/10.1002/jclp.22316

Kampman, H., Hefferon, K., Wilson, M., \& Beale, J. (2015). “I can do things now that people thought were impossible, actually, things that I thought were impossible": A meta-synthesis of the qualitative findings on posttraumatic growth and severe physical injury. Canadian Psychology/Psychologie Canadienne, 56(3), 283-294. https://doi.org/10.1037/cap0000031

Kaniasty, K., \& Norris, F. H. (2009). Distinctions that matter: Received social support, perceived social support, and social embeddedness after disasters. In Y. Neria, S. Galea, \& F. H. Norris (Ed.), Mental health and disasters (pp. 175-200). Cambridge University Press.

Kashdan, T. B., Julian, T., Merritt, K., \& Uswatte, G. (2006). Social anxiety and posttraumatic stress in combat veterans: Relations to well-being and character strengths. Behaviour Research and Therapy, 44, 561-583. https://doi.org/10.1016/j.brat.2005.03.010

Krentzman, A. R. (2013). Review of the application of positive psychology to substance use, addiction, and recovery research. Psychology of Addictive Behaviors, 27(1), 151-165. https://doi.org/10.1037/a0029897

Krouse, H. J. (2020). COVID-19 and the Widening Gap in Health Inequity. Otolaryngology-Head and Neck Surgery, 163(1), 65-66. https://doi.org/10.1177/0194599820926463

Lau, J. T., Yang, X., Pang, E., Tsui, H. Y., Wong, E., \& Wing, Y. K. (2005). SARS-related perceptions in Hong Kong. Emerging infectious diseases, 11(3), 417-424. https://doi.org/10.3201/eid1103.040675

Martinez- Marti, M. L., \& Ruch, W. (2014). Character strengths and well-being across the lifespan: Data from a representative sample of German-speaking adults living in Switzerland. Frontiers in Psychology, 5, 1253. https://doi.org/10.3389/fpsyg.2014.01253

Mongrain, M., \& Anselmo- Matthews, T. (2012). Do positive psychology exercises work? A replication of Seligman et al. (2005). Journal of Clinical Psychology, 68, 382-389. https://doi.org/10.1002/jclp.21839.

McGrath, R. E. (2019). Technical report: The VIA Assessment Suite for Adults: Development and initial evaluation (rev. ed.). VIA Institute on Character. https://evada-assets.global.ssl.fastly.net/76d1ea39a4eb-4270-b9dc-899653415f8f/assets/Technical\%20Report\%20Revised\%20Edition\%202019_1.pdf 
McLeod, M., Gurney, J., Harris, R., Cormack, D., \& King, P. (2020). COVID-19: we must not forget about Indigenous health and equity. Australian and New Zealand Journal of Public Health, 44(4), 253-256. https://doi.org/10.1111/1753-6405.13015

Meyer, M. R. U., Meyer, A. R., Wu, C., \& Bernhart, J. (2018). When helping helps: Exploring health benefits of cancer survivors participating in for-cause physical activity events. BMC Public Health, 18(1), 663. https://doi.org/10.1186/s12889-018-5559-6

Naushad, V. A., Bierens, J. J. L. M., Nishan, K. P., Firjeeth, C. P., Mohammad, O. H., Maliyakkal, A. M., ChaliHadan, S., \& Schreiber, M. D. (2019). A systematic review of the impact of disaster on the mental health of medical responders. Prehospital and Disaster Medicine, 34(6), 632-643. https://doi.org/10.1017/S1049023X19004874

Navaranjan, D., Rosella, L. C., Kwong, J. C., Campitelli, M., \& Crowcroft, N. (2014). Ethnic disparities in acquiring 2009 pandemic H1N1 influenza: A case-control study. BMC Public Health, 14(1), 214. https://doi.org/10.1186/1471-2458-14-214

Niemiec, R. M. (2018). Character strengths interventions: A field guide for practitioners. Hogrefe.

Niemiec, R. M., \& McGrath, R. E. (2019). The power of character strengths: Appreciate and ignite your positive personality. VIA Institute on Character.

Odou, N., \& Vella- Brodrick, D. A. (2013). The efficacy of positive psychology interventions to increase well- being and the role of mental imagery ability. Social Indicators Research, 110(1), 111-129. https://doi.org/10.1007/s11205-011-9919-1

Park, C. L., Russell, B. S., Fendrich, M., Finkelstein-Fox, L., Hutchison, M., \& Becker, J. (2020). Americans' COVID-19 Stress, Coping, and Adherence to CDC Guidelines. Journal of General Internal Medicine, 35(8), 2296-2303. https://doi.org/10.1007/s11606-020-05898-9

Klaiber, P., Wen, J. H., DeLongis, A., \& Sin, N. L. (2020). The Ups and Downs of Daily Life During COVID-19: Age Differences in Affect, Stress, and Positive Events. The Journals of Gerontology: Series B. https://doi.org/10.1093/geronb/gbaa096

Peterson, C., \& Seligman, M. E. P. (2004). Character strengths and virtues: A handbook and classification. American Psychological Association/Oxford University Press.

Prati, G., \& Pietrantoni, L. (2010). The relation of perceived and received social support to mental health among first responders: A meta-analytic review. Journal of Community Psychology, 38(3), 403-417. https://doi.org/10.1002/jcop.20371

Poteat, T., Millett, G. A., Nelson, L. E., \& Beyrer, C. (2020). Understanding COVID-19 risks and vulnerabilities among black communities in America: The lethal force of syndemics. Annals of Epidemiology, 47, 1-3. https://doi.org/10.1016/j.annepidem.2020.05.004

Quevillon, R. P., Gray, B. L., Erickson, S. E., Gonzalez, E. D., \& Jacobs, G. A. (2016). Helping the helpers: Assisting staff and volunteer workers before, during, and after disaster relief operations. Journal of Clinical Psychology, 72(12), 1348-1363. https://doi.org/10.1002/jclp.22336

Quoidbach, J., \& Gross, J. J. (2015). Positive Interventions: An Emotion Regulation Perspective. Psychological Bulletin, 141(3), 655-693. https://doi.org/10.1037/a0038648

Rashid, T., \& Seligman, M. E. P. (2018). Positive psychotherapy: Clinical manual. Oxford University Press.

Rateau, M. R. (2017). An analysis of stories from those who have encountered catastrophic loss from flood. Archives of Psychiatric Nursing, 31(6), 561-565. https://doi.org/10.1016/j.apnu.2017.07.009

Samet, J. H., Blokhina, E., Cheng, D. M., Walley, A. Y., Lioznov, D., Gnatienko, N., ... Krupitsky, E. (2019). A strengths-based case management intervention to link HIV-positive people who inject drugs in Russia to HIV care. AIDS, 33(9), 1467-1476. https://doi.org/10.1097/QAD.0000000000002230

Samson, F. L. (2018). An association between multiculturalism and psychological distress. PLOS One, 13(12), e0208490. https://doi.org/10.1371/journal.pone.0208490

Sanford, A. (2020) Coronavirus: Half of humanity now on lockdown as 90 countries call for confinement. Available at: https://www.euronews.com/2020/04/02/coronavirus-in-europe-spain-s-death-toll-hits10-000-after-record-950-new-deaths-in-24-hou (accessed 28 September 2020)

Schotanus-Dijkstra, M., Drossaert, C. H., Pieterse, M. E., Walburg, J. A., \& Bohlmeijer, E. T. (2015). Efficacy of a multicomponent positive psychology self- help intervention: Study protocol of a randomized controlled trial. JMIR Research Protocols, 4(3), e105. https://doi.org/10.2196/resprot.4162 
Schutte, N. S., \& Malouff, J. M. (2019). The impact of signature character strengths interventions: A metaanalysis. Journal of Happiness Studies, 20(4), 1179-1196. https://doi.org/10.1007/s10902-018-9990-2

Shuchman, M. (2020). Low- and middle-income countries face up to COVID-19. Nature Medicine. https://doi.org/10.1038/d41591-020-00020-2

Shoshani, A., \& Slone, M. (2016). The Resilience Function of Character Strengths in the Face of War and Protracted Conflict. In Frontiers in Psychology, 6, 2006. https://doi.org/10.3389/fpsyg.2015.02006

Sleijpen, M., Boeije, H. R., Kleber, R. J., \& Mooren, T. (2016). Between power and powerlessness: A metaethnography of sources of resilience in young refugees. Ethnicity \& Health, 21(2), 158-180. https://doi.org/10.1080/13557858.2015.1044946

Southwick, S. M., Satodiya, R., \& Pietrzak, R. H. (2016). Disaster mental health and positive psychology: An afterward to the special issue. Journal of Clinical Psychology, 72(12), 1364-1368. https://doi.org/10.1002/jclp.22418

Somma, A., Gialdi, G., Krueger, R. F., Markon, K. E., Frau, C., Lovallo, S., \& Fossati, A. (2020). Dysfunctional personality features, non-scientifically supported causal beliefs, and emotional problems during the first month of the COVID-19 pandemic in Italy. Personality and Individual Differences, 165, 110139. https://doi.org/10.1016/j.paid.2020.110139

Skeffington, P. M., Rees, C. S., Mazzucchelli, T. G., \& Kane, R. T. (2016). The primary prevention of PTSD in firefighters: Preliminary results of an RCT with 12-month follow-up. PLOS One, 11(7), e0155873. https://doi.org/10.1371/journal.pone.0155873

Toback, R. L., Graham-Bermann, S., \& Patel, P. D. (2016). Outcomes of a Character Strengths-Based Intervention on Self-Esteem and Self-Efficacy of Psychiatrically Hospitalized Youths. Psychiatric Services, 67(5), 574-577. https://doi.org/10.1176/appi.ps.201500021

Torales, J., O'Higgins, M., Castaldelli-Maia, J. M., \& Ventriglio, A. (2020). The outbreak of COVID-19 coronavirus and its impact on global mental health. International Journal of Social Psychiatry, 66(4), 317-320. https://doi.org/10.1177/0020764020915212

Uliaszek, A. A., Rashid, T., Williams, G. E., \& Gulamani, T. (2016). Group therapy for university students: A randomized control trial of dialectical behavior therapy and positive psychotherapy. Behaviour Research and Therapy, 77, 78-85. https://doi.org/10.1016/j.brat.2015.12.003

van Dorn, A., Cooney, R. E., \& Sabin, M. L. (2020). COVID-19 exacerbating inequalities in the US. The Lancet, 395(10232), 1243-1244. https://doi.org/10.1016/S0140-6736(20)30893-X

Vertilo, V., \& Gibson, J. M. (2014). Influence of character strengths on mental health stigma. Journal of Positive Psychology, 9(3), 266-275. https://doi.org/10.1080/17439760.2014.891245

Wang, Y., Zhao, X., Fen, Q., et al. (2020). Psychological 2019 outbreak in China. Journal of Health Psychology, 25(6), 733-737. https://doi.org/10.1177/1359105320919177

Winslow, C. J., Kaplan, S. A., Bradley- Geist, J., Lindsey, A. P., Ahmad, A. S., \& Hargrove, A.K. (2016). An examination of two positive organizational interventions: For whom do these interventions work? Journal of Occupational Health Psychology, 22(2), 129. https://doi.org/10.1037/ocp0000035

Witowska, J., Schmidt, S., \& Wittmann, M. (2020). What happens while waiting? How self-regulation affects boredom and subjective time during a real waiting situation. Acta Psychologica, 205, 103061. https://doi.org/10.1016/j.actpsy.2020.103061

Yang, M. (2020). Resilience and Meaning-Making Amid the COVID-19 Epidemic in China. Journal of Humanistic Psychology, 60(5), 662-671. https://doi.org/10.1177/0022167820929215

Yan, T., Chan, C. W. H., Chow, K. M., Zheng, W., \& Sun, M. (2020). A systematic review of the effects of character strengths-based intervention on the psychological well-being of patients suffering from chronic illnesses. Journal of Advanced Nursing, 76(7), 1567-1580. https://doi.org/10.1111/jan.14356.

Yearby, R., \& Mohapatra, S. (2020). Law, Structural Racism, and the COVID-19 Pandemic. Journal of Law and the Biosciences, 7(1), 1-20. https://doi.org/10.1093/jlb/lsaa036

Zalaquett, C. P., Fuerth, K. M., Stein, C., Ivey, A. E., \& Ivey, M. B. (2008). Reframing the DSM-IV-TR from a multicultural/social justice perspective. Journal of Counseling $\mathcal{E}$ Development, 86, 364-371.

https://doi.org/10.1002/j.1556-6678.2008.tb00521.x 


\section{Appendix A}

\section{Strengths-Based Actions to Practice during Physical Distancing}

In the following, we sometimes use the word "pod" to indicate the person or people with whom you are sheltering in place. At the end of each action, a number of strengths with hyperlinks are listed. You can explore more about these strengths using the hyperlinks listed in parentheses. Following action can broadly parsed in following themes. The numerical number indicates the action listed.

Stress Management: 1, 8, 11, 15, 23, 67, 68, 79, 97, 99

Staying Healthy: 2, 10, 14, 24, 26, 28, 38, 43, 44, 45, 56, 61, 63, 65, 77, 78, 80,

Individual Growth: 17, 19, 20, 34, 39, 40, 49, 53, 57, 60, 64, 74, 75, 76, 87, 88, 89, 92, 95, 100

Skill Building: 3, 50, 54, 70, 71, 72, 91, 93, 97

Interaction with Others: 4, 5, 6, 7, 9, 12, 13, 16, 21, 27, 29, 30, 32, 33, 35, 36, 41, 47, 48, 52, 58, 59, 62, $66,69,84,90,94,96,101$

Social Causes: 18, 22, 25, 31, 37, 42, 46, 51, 55, 73, 81, 82, 83, 85, 86, 98

1. Cultivate mindfulness. Try to remember to take a moment or two every hour or so during waking hours to notice your breathing, your surroundings, your physical and emotional experience. Be present in your body and in your environment. (curiosity, self-regulation, zest)

2. Establish a physical exercise routine that you can do at home. Incorporate variations that are meaningful and motivating for you. You can also integrate physical exercise with yoga poses or a deep breathing exercise; share with your pod. (zest, teamwork, self-regulation)

3. Build something using found objects in your environment. Invite others to participate. (creativity, teamwork, curiosity)

4. Ask others about their fears. Give reassurance, use touch, refrain from judgement. Help yourself and others cultivate calm acceptance. (social intelligence, kindness, hope, perspective)

5. Leave a surprise gift for someone in your pod. Hint: a special food treat is particularly welcome, perhaps a chocolate on the pillow of a child. (love, kindness)

6. Prepare and deliver a meal to someone in your community. Let them know to expect it but surprise them with what you make. Leave it on the doorstep with a sweet note. (kindness, love, social intelligence)

7. Snuggle up with someone special if you are lucky enough to be in physical connection with at least one loved one. Be grateful for their presence while you cuddle. (love, gratitude)

8. Take a moment away from the digital world and enjoy being quiet. Pay attention to the opportunity to cultivate joy in the ordinary; look out the window at the sky, the birds, the landscape. (curiosity, zest, appreciation of beauty and excellence).

9. Send a book to someone with the intention of making them smile or laugh. This is a great opportunity to support a local bookstore. If you don't have access to a bookstore, send a digital book. (humor, teamwork, kindness)

10. Dance! Make it a family experience by inviting the whole pod. Tune into a group dance on YouTube or Facebook. (zest, leadership)

11. Listen to music while you are engaged in a tedious or boring task like folding laundry or washing dishes. Notice if savoring the music helps make the task more pleasant. (appreciation of beauty and excellence, curiosity, perseverance) 
12. Check in with neighbors to see if they need anything when you go shopping. (kindness, teamwork)

13. Think up a project that will engage the interests and talents of everyone in your pod. You could play a game, work on a puzzle, or prepare a meal together. Make sure to thank everyone for their participation. (teamwork, leadership, gratitude)

14. Take a walk outside if you can, or walk around your living space. Notice things that you find pleasing. (appreciation of beauty and excellence, perseverance)

15. Cultivate mindfulness when you are eating. Savor. Take your time, finishing each bite before taking the next bite. (self-regulation, gratitude, prudence)

16. Challenge members of your pod, especially children, to make you laugh. Be generous about this! (humor, kindness, leadership, social intelligence)

17. Practice compassion. At least once a day, set your intention to refrain from doing harm to others in your thoughts, words, and actions. (kindness, self-regulation)

18. Create a group on social media devoted to finding a way to help others in the world during this difficult time. (leadership, kindness, teamwork, hope)

19. Maintaining your living space can be a lot of work, especially if you take on large projects. Do more than your share. Don't take credit, just do it! (perseverance, teamwork, humility)

20. Think about a significant life event that changed you. Write it down or tell it to a loved one. (honesty, perspective, love)

21. Notice that you have two ears and only one mouth. Try to make use of this observation. For at least one hour a week, try to listen twice as much as you speak. (social intelligence, perspective, self-regulation)

22. Use social media to create an exchange of skills and resources to make yourself available to those who need help, for example \#caremongering (teamwork, kindness, leadership, social intelligence, fairness)

23. Create a ritual of solace to help handle uncertainty. This can be religious or spiritual. Invite loved ones to participate. This is a terrific way to use telecommunication to include friends and family outside your pod. (spirituality, hope, creativity)

24. Try to remember a favorite childhood food. Share the memory with someone. (gratitude, appreciation of beauty and excellence, love)

25. Explore a Black, Indigenous or diverse artist, poet or writer (e.g., Bob Marley, Maya Angelou, James Baldwin) who has fought for equity and justice through their creativity shown resistance through their art outside at night and watch the stars. (creativity, appreciation of beauty and excellence, leadership)

26. Rearrange a space in your home. (appreciation of beauty and excellence, creativity)

27. Make a special breakfast to celebrate a birthday or anniversary. Include an IOU for a more substantial celebration after quarantine is over. (love, kindness, hope)

28. Remember or study up on a happy event in history. Write about it. (love of learning, hope, creativity)

29. Make a gratitude list. Share it with loved ones, especially if you are grateful for their presence in your life. Invite them to do the same. (gratitude, love, social_intelligence) 
30. Call or video chat with a friend. Ask them questions that will elicit the story of a special time in their life. Listen to the whole story without interrupting. (social_intelligence, kindness, self-regulation)

31. Work on a creative project which focuses on inclusion and COVID-19. For example you can partner with a friend, preferably from a diverse cultural background and showcase inclusive and diverse aspects of resilience in coping with COVID-19 (creativity, love of learning, teamwork)

32. Think of a friend, colleague, family member, or acquaintance who is alone. Send them a text or email or call them to let them know you care. (love, kindness, social intelligence)

33. Think up questions to ask loved ones that you anticipate will be fun for them to answer. (kindness, curiosity, love)

34. Cultivate a positive attitude about your own health and about the health of your loved ones. (hope)

35. Do something to make someone laugh or smile. (humor, kindness)

36. Allow your loved ones to express themselves freely; don't judge. (kindness, social intelligence, judgement, self-regulation, fairness, prudence)

37. Reflect and discuss with your friends' what steps you can take to end healthcare inequalities. If possible, call or connect online with a Black, Hispanic, Indigenous or any one from a marginalized community to learn about systemic barriers they face and brainstorm ways to remove or minimize them. Share your reflections or suggestions with your friends with the intention of building allyship! (fairness, teamwork, bravery)

38. Deepen your connection with nature, for example, by walking, gardening, birdwatching, or foraging. Do this for at least 10 minutes a day. (appreciation of beauty and excellence, perseverance)

39. Slow down, you move too fast! When you are reading, cleaning, typing, browsing the web, be aware of your pace. Choose at least one activity daily that you do at a leisurely pace. (prudence, self-regulation)

40. Are you holding any grudges? Is there tension in any of your relationships? Use this time to reach out and to let it go. (forgiveness, kindness)

41. Give your undivided attention to someone you love. This is a great opportunity to use video chat. (love, self-regulation)

42. If one of your friends is home-bound and they are having relationship challenges. Please keep find ways so they can share any potential abuse with you. If they are afraid to share verbally, establish creative non-verbal ways to signal to each other so appropriate steps can be taken (fairness, social intelligence)

43. Fight cabin fever! Go for a hike, run up and down stairs, throw a ball, take an online exercise or yoga class, or go for a run while maintaining physical distance. (zest, creativity, self-regulation)

44. Stop eating before you are full. (self-regulation, prudence)

45. Reminisce about three places you've been that you've enjoyed. Share the memory by sending or showing someone a video or photo of those places. (gratitude, appreciation of beauty and excellence) 
46. Express appreciation to front-line workers. Take a cue from people in Italy and Spain, who have stood on balconies and applauded. Social media is a good platform for this. (gratitude, kindness)

47. Create a playlist of favorite songs or videos to share with a partner or friend. (love, creativity, kindness)

48. Take over a chore to relieve a partner or a member of your pod. (love, kindness)

49. Try to be open-minded. Don't criticize others. Instead, try to empathize and be compassionate. This is relevant both in person and via telecommunication, especially social media. (social intelligence, self-regulation, judgement, fairness, humility)

50. Revive a lost or forgotten pragmatic craft, such as calligraphy, weaving, sewing, knitting, woodworking... Consider using it to contribute. For example, sew masks and donate to health care workers. (creativity, love of learning, self-regulation)

51. Donate time or money to an organization that is helping those in greatest need. (teamwork, kindness)

52. Acknowledge the inevitability of tension when living together 24/7. Establish ground rules for conflict resolution, including celebrating your differences. (social_intelligence, forgiveness, fairness, prudence)

53. Practice restraint when you feel emotionally reactive. Choose silence or mindful listening. (self-regulation, kindness, judgement, prudence, fairness)

54. Invent a recipe without buying new ingredients. (creativity, prudence)

55. Go through your clothes and donate anything you haven't worn in a year. Do the same with books and household objects. (kindness, self-regulation)

56. Notice the way aromas influence your mood. (appreciation of beauty and excellence, curiosity)

57. Notice small things that improve your mood. (prudence, humility)

58. Watch a movie with your partner or pod. (love, appreciation of beauty and excellence)

59. Watch and/or participate in a virtual concert. (appreciation of beauty and excellence, zest)

60. Set your intention to be aware of frustration and use it as an opportunity to practice patience. (prudence, self-regulation, judgement)

61. Find or frame old family photos. Use them to decorate some spaces in your home. (creativity, appreciation of beauty and excellence)

62. Inspire the pod to work together to sort and rearrange or redecorate a space in your home. (leadership, teamwork, appreciation of beauty and excellence, creativity)

63. Set a goal to take exercise breaks throughout the day. Stop what you're doing and do five minutes of stretching or strength building (such as push-ups, planks, and squats) five or six times a day. (self-regulation, prudence)

64. Resist the temptation to share information (personally or on social media), especially about COVID-19, if it is likely to cause confusion or fear. Don't manifest panic by hoarding. (kindness, judgement, perspective)

65. Using virtual or real-life visual images, create a collage depicting the life of each of your family members or loved ones. (love, perspective, creativity, kindness)

66. Ask family members and friends how they survived other hard times in their lives. Explore what helped them through: what worked for them and what they learned about themselves. (perspective, love of learning, curiosity) 
67. Savor physical interaction with a pet or look for cute animals online. (love, humor)

68. Honor and savor time alone and with loved ones. (gratitude, zest)

69. Tuck a flower or treat between the sheets to surprise your bedmate. (humor, love)

70. Plant and maintain an herb garden (either outdoors or indoors). Have fun cooking with your homegrown herbs. (appreciation of beauty and excellence, creativity, zest)

71. Think about maximizing the opportunities inherent in this time. Get extra rest and take time to share with your pod and/or friends. Tell your deepest secrets. Be vulnerable. Try to think of new things to do together. (honesty, creativity, gratitude, social intelligence, love)

72. Do you have a toolbox? Clean, update, and organize it. Don't have one? Think about putting one together; it's an important resource! (prudence)

73. Learn about ten historical incidents/events or actions that have reinforced anti-black racism, homophobia, xenophobia, anti-Semitism, maltreatment of indigenous people. Reflect and write a few practical steps that you can do combat it (fairness, judgement, perspective)

74. Learn how to talk to yourself using positive messages. Practice positive self-talk regularly. (self-regulation, love of learning)

75. Embrace the opportunity for solitude. Take time to reflect on your behavior. Think about the implications of your actions; what modifications might be useful? (humility, prudence, perspective, judgement)

76. Look at the ways you've been critical of yourself and others. Make a list of musts and shoulds that have held you back from making personal progress or collaborating well with others. (honesty, judgement, teamwork, humility)

77. Play music and/or sing, alone or with others. (creativity, appreciation of beauty and excellence, teamwork)

78. Play board games or card games. (humor, teamwork, zest)

79. Use your phone or tablet to remind you to do your mindfulness practice, do some deep breathing, and be aware of your posture throughout the day. (self-regulation, prudence)

80. Develop a morning coffee or tea ritual alone or with a partner (real or virtual). Watch the sunrise or enjoy nature. (appreciation of beauty and excellence, love)

81. Write a letter of gratitude to an essential or health care worker, or to a first responder. (gratitude, kindness)

82. Provide or pay for a service such as laundry, errands, cleaning, or yard work for someone who could use the help, perhaps someone who is infirm, overwhelmed, infected, or overworked. (kindness, teamwork)

83. Participate in an online campaign or activity (e.g., attending a webinar, workshop, or a townhall) which discusses ways to combat racism, discrimination, marginalization, or "othering" of people who might be different in some ways (honesty, fairness, judgement, teamwork)

84. When you have a reactive moment (and you will), remember to pause for at least a full minute (or three good deep breaths) before you respond. (self-regulation, social_intelligence)

85. Find a way to help a homeless person. (kindness, teamwork)

86. Make a list of things that don't concern you specifically, but that are issues for others in the community or the world. (perspective, teamwork, fairness) 
87. Spend 20-30 minutes reading something that will broaden your perspective. Look for a book, newspaper, blog, or magazine to widen your view of the world. (love of learning, perspective)

88. Practice radical acceptance of negative thoughts and feelings. Resist the temptation to be discouraged by them. Search for meaning rather than blame. (humility, perseverance, perspective, hope)

89. Assume good intentions on the part of others, including those who are different from you. Have an open heart and a compassionate view and don't discriminate based on sex, race, ethnicity, or nationality. Set boundaries with firmness; don't be mean. (fairness, kindness)

90. Ask a loved one to tell you how they are feeling; ask questions for clarification and to draw them out. Be compassionate and non-judgemental. Don't interrupt or disrupt with your own agenda. (social_intelligence, kindness, love, judgement)

91. Use this time to learn a new skill. Read a "do-it-yourself/ book or watch videos on the web. If there are skills you've always wanted to improve or master, this is the time! Might we suggest learning to make masks and then donating them to your local hospital? Instructions abound on the internet. (love of learning, perseverance, teamwork)

92. Direct your thoughts and energies to focus on others rather than on yourself. This will help you with fear and grief during difficult times. Remember that the reason we are in quarantine is to save lives. Consider the fact that by staying home, you are making an important contribution. (humility, bravery, teamwork)

93. Rather than relying on your devices, memorize the phone numbers of your loved ones. (love of learning)

94. Socialize with optimists via social media, social distancing, or telecommunication. (hope)

95. Reflect on your strengths. Be honest with yourself about them. (honesty, gratitude, prudence)

96. Ask for honest feedback from loved ones and/or colleagues about your capacity to listen, your integrity, and your communication skills (verbal and non-verbal). Heed their words. (social_intelligence, honesty, teamwork, bravery)

97. Being at home for a prolong period of time will inevitably present you with a problem which you could have easily otherwise solved (e.g., fixing an appliance, helping a loved one in trouble). Monitor your mood. If you are becoming worried or anxious and the problem is not urgent, take a break. Engage in a short activity which generate positive emotions. Return to the problem, you will most likely find an acceptable solution (social_intelligence, judgement)

98. Cook for someone who is hungry, sick, or busy. Send a meal (help a restaurant) to someone in another part of the world. Volunteer your time. Donate blood. (teamwork, kindness)

99. Practice the yoga page savasana: Lie flat on your back, legs relaxed, arms by your sides, palms facing up and open, toes relaxed to the sides. Breathe deeply for five minutes. (selfregulation, prudence)

100. Change a complaint into an opportunity for playfulness. Tell a joke. Don't take yourself too seriously. (humor, self-regulation, humility)

101. Try to find a way to surprise and delight your loved ones and yourself. Strive for some lightheartedness. Look for the absurd, the goofy, and the silly. Fight despair with joy, fun, and love. (humor, kindness, teamwork, love) 